\title{
DIREITO DO IDOSO E POLÍTICAS PÚBLICAS DE SUSTENTABILIDADE URBANA
}

\author{
Ana Maria Viola de Sousa ${ }^{1}$ \\ Rodolfo Anderson Bueno de Aquino
}

\section{RESUMO}

Envelhecimento e urbanização são dois temas de grande relevância, interligados, compreendendo duas faces de uma mesma moeda. Ambos provocam efeitos preocupantes à vida da população, exigindo intervenção ética e comprometimento responsável de todos: idoso, família, autoridades, sociedade, órgãos públicos e privados, organizações sociais. O presente trabalho visa uma reflexão sobre a complementaridade dos temas, acentuando o valor da sustentabilidade urbana necessário para a defesa e a garantia dos direitos dos idosos legalmente estabelecidos. Assentado na pesquisa bibliográfica, as proposições poderão ser referenciais na elaboração de políticas públicas que preservem a dignidade do idoso.

Palavras-chave: Políticas Públicas; Direito do idoso; Envelhecimento; Sustentabilidade; Urbanização.

\section{THE RIGHT OF THE ELDERLY AND PUBLICS POLICIES FOR URBAN SUSTAINABILITY}

\begin{abstract}
Aging and urbanization are two themes of great relevance, interconnected, comprising two faces of same coin. Both cause worrying effects on the life of population, requiring ethical intervention and responsible commitment of all: elder, family, authorities, society, public and private agencies, social organizations. This work aims at a reflection on the complementarity of themes, emphasizing the value of the urban sustainability necessary for the defense and the guarantee of rights of legally established older people. Based on the bibliographical research, the propositions may be referential in the elaboration of public policies that preserve the dignity of the elders.
\end{abstract}

Keywords: Public Policies; Right of the elderly; Aging; Sustainability; Urbanization.

\section{Introdução}

O envelhecimento populacional é um dos fenômenos que provoca maior preocupação entre os estudiosos e pesquisadores de diferentes áreas de conhecimento. É sabido que o envelhecimento acarreta impactos nos mais variados setores: econômico,

\footnotetext{
${ }^{1}$ Pós Doutora em Direito pela Universidade de Coimbra/PORTUGAL, Doutora em Direito pela PUC-SP e Professora na UNISAL, UNIVAP e UNIP. Advogada. anaviola@ aasp.org.br

${ }^{2}$ Mestre em Direito pelo UNISAL/SP. Professor no UNISAL/SP - Centro Universitário Salesiano de São Paulo e na FCN/SP - Faculdade Canção Nova. Advogado. rodolfoabueno@gmail.com
} 
político, cultural, social, civil, assistencial, previdenciário, jurídicos, entre outros, ocasionando distúrbios nos sistemas institucionais.

Pela previsão das Nações Unidas, feita em 2017, a população total mundial atinge 7,6 bilhões de pessoas, das quais, 962 milhões estão com idade de 60 anos ou mais, representando $13 \%$ de toda a população (ONU, 2017, p. 17). Projetando para o futuro, o documento estima que os idosos em 2030 serão 1,4 bilhões e em 2050 de 2,1 bilhões de pessoas (idem, p. 11).

Também no Brasil vem sendo observado o aumento do número de idosos. Censos realizados pelo IBGE - Instituto Brasileiro de Geografia e Estatística demonstram que no ano de 2000, os idosos representavam 8,6\% do total da população; em 2010 esse índice subiu para 12,1\%, que corresponde em números absolutos a 18 milhões de pessoas (IBGE, 2016, s/p). As projeções feitas pelo IBGE também informam que para 2030 e 2050 a previsão, respectivamente, é de $18 \%$ e quase $30 \%$ de idosos em relação à população total brasileira (idem).

Todos esses números despertam a preocupação no trato da questão do envelhecimento. Diversas áreas do conhecimento tem-se debruçado em pesquisas, sob os mais diferentes pontos de vista, para decifrar, compreender e propor soluções para o bem-estar dessa parcela da população que cresce em níveis superiores a quaisquer outras faixas etárias.

Paralelamente, os últimos tempos vêm sendo acompanhados do fenômeno de concentração cada vez maior de pessoas nas cidades ou zonas urbanas. Conforme destaca a Organização Mundial da Saúde, em 2007, metade de toda a população do mundo vivia nas cidades, projetando-se para 2030, uma razão de 3 a cada 5 pessoas, aquelas que estarão habitando zonas urbanas (OMS, 2008, p. 8). De acordo com o Relatório Mundial das Cidades (ONU (a), 2016, editorial), atualmente $54 \%$ da população vive nas cidades, cifra que atingirá $66 \%$ até 2050.

No Brasil os índices são ainda maiores. O IBGE (2016, s/p) informa que a taxa de urbanização cresceu de 82,5 para 84,7, de 2005 a 2015, respectivamente; a maior proporção de pessoas que vivem em áreas urbanas foi constatada no Rio de Janeiro que atingiu 97,4, seguida de São Paulo onde a taxa de urbanização foi de 96,6, índices superiores à média indicada no Relatório Mundial. 
Em geral as pessoas se movem para a zona urbana em busca de maiores oportunidades de estudo, de trabalho e de vida, considerando que a zona urbana tem recebido melhores atenções por parte dos órgãos públicos, em detrimento às zonas rurais. Em se tratando de pessoa idosa a escolha pela zona urbana, tem igualmente essas opções, acrescentando outras, principalmente pela melhor acessibilidade aos sistemas de saúde, ante o declínio da condição física decorrente da idade.

Essa dinâmica transição da zona rural para a urbana traz outros problemas ocasionados pela concentração populacional nas cidades. As cidades são cada vez maiores, mais complexas, mais extensas, enquanto os serviços públicos avançam a passos lentos, fazendo com que as pessoas não encontrem o bem-estar que tanto procuram. $\mathrm{O}$ aumento da longevidade afeta também a população que já vive na cidade.

Assim, este trabalho tem o propósito de discutir o fenômeno do envelhecimento associado ao da urbanização, analisando a complementaridade dos assuntos, acentuando o valor da sustentabilidade urbana necessário para a defesa e a garantia dos direitos dos idosos legalmente estabelecidos. Assentado na pesquisa teórico-doutrinária, a sistematização do conhecimento obedecerá raciocínio dedutivo, cujas proposições poderão ser referenciais na elaboração de políticas públicas que preservem a dignidade do idoso.

\section{$1 \mathrm{O}$ idoso e as legislações correlatas ao desenvolvimento e sustentabilidade}

A Constituição Federal, em seu art. 230, estabelece que é da família, da sociedade e do Estado, o dever de amparar as pessoas idosas, assegurando sua participação na comunidade, defendendo sua dignidade e bem-estar, garantindo-lhes o direito à vida. Essa premissa está também amplamente disposta no Estatuto do Idoso - Lei 10.741/2003.

Outros dispositivos constitucionais, ainda que não se refiram expressamente aos idosos, seus ditames são de grande importância para essa parcela da população, especialmente os dos artigos 182 e 225 da Constituição Federal.

$\mathrm{O}$ art. 182 da Constituição Federal refere-se à política de desenvolvimento urbano, a qual deve objetivar a promoção do bem-estar de todos os seus habitantes. 
Quando se fala em desenvolvimento, o pensamento logo se volta para o aspecto econômico. Isto porque a teoria do desenvolvimento tem como referência a acumulação de capital, que, por seu turno, promove a distribuição de renda e automaticamente melhora os padrões de vida. Assim, o desenvolvimento tinha como consequência direta o crescimento econômico e a elevação do nível de riqueza (OLIVEIRA, 2017, p. 56-58).

No período pós-guerra, porém, novas contribuições vieram a se somar, influenciadas principalmente pela disseminação dos direitos humanos, mudando a forma de pensar. Estudiosos da economia trouxeram à tona discussões dando uma visão mais complexa sobre desenvolvimento. Exemplos dessas contribuições podem ser atribuídas, por exemplo, a Amartya Sen, o qual aborda a questão do desenvolvimento como medida necessária para a remoção das barreiras que limitam as possibilidades de escolha, de forma que o crescimento econômico tem papel decisivo na expansão das liberdades, já que a opulência permite maior acesso a bens e serviços (OLIVEIRA, 2017, p. 98-99).

Reporte-se também a contribuição de Ignacy Sachs (OLIVEIRA, 2017, p. 102) que amplia o horizonte do desenvolvimento, propondo uma abordagem mais universalista, concebendo-o como um processo que é visto não apenas sob ótica do social, como também do ambiental. Draibe e Riesco (2011, p. 226) afirmam que em se tratando de desenvolvimento, deve-se pensar o econômico articulado com o social, de modo a observar também a expansão dos direitos sociais e políticos. Nessa perspectiva o desenvolvimento tem por objetivo, proporcionar a todos os cidadãos sua inclusão, sua participação, o desfrutar dos direitos sociais mas, com a necessária preservação dos recursos naturais.

Nesse particular, a referência à defesa e à preservação do meio ambiente sadio e equilibrado é estabelecida na Constituição Federal no art. 225, sendo, portanto um direito não apenas dos idosos, mas de toda a população.

Com foco nos idosos, considerando sua maioria em zonas urbanas, a Organização Mundial da Saúde, divulgou em 2008, o Guia Global: Cidade Amiga do Idoso. Este documento esclarece que

uma cidade amiga do idoso estimula o envelhecimento ativo ao otimizar oportunidades para saúde, participação e segurança, para aumentar a qualidade de vida à medida que as pessoas envelhecem (OMS, 2008, p. 7). 
Isto significa que quando o desenvolvimento urbano tiver como preocupação o bemestar dos idosos, também estará melhorando a qualidade de vida de todos, já que deverá promover mudanças construtivas na sociedade e se preparar para as necessidades dos futuros residentes mais velhos (MONTEIRO, 2017, p. 25).

O Brasil ainda não aderiu ao Guia elaborado pela OMS. Há, na verdade um Projeto de Lei 1313/2011, proposto pelo Deputado Ricardo Tripoli que está em tramitação na Câmara dos Deputados, objetivando a adesão do Brasil a esse Guia. Aprovado pela Comissão de Defesa dos Direitos da Pessoa Idosa em 16/08/2017, e também pela Comissão de Seguridade Social, atualmente, encontra-se na Comissão de Constituição, Justiça e de Cidadania ${ }^{3}$.

Independentemente, é possível que o desenvolvimento urbano possa atender os propósitos da Cidade Amiga do Idoso, considerando a existência de outras legislações que podem servir de sustentação. Referenciam-se a Lei 10.257, de 10 de julho de 2001, conhecida como Estatuto da Cidade, a Lei 12.587/2012 que dispõe sobre a Política Nacional de Mobilidade Urbana, e o Decreto 8.114, de 2013, que dispõe sobre o Compromisso Nacional para o Envelhecimento Ativo.

O Estatuto da Cidade dispõe sobre gestão urbana sustentável, estabelece as políticas de regulamentação do uso das propriedades urbanas, objetivando evitar o crescimento desordenado e impedir efeitos negativos sobre a sociedade e o meio ambiente (BARRETO; PORTO, 2016, p. 237). Analisam Proni e Faustino (2016, p. 186) que apesar de constituir um marco na política urbana no Brasil, a lei não logrou êxito em promover mudanças estruturais nas cidades brasileiras, seja pela ausência de estratégias consistentes para o planejamento e desenvolvimento, seja pela redução dúbia de alguns artigos que ensejaram questionamentos jurídicos, seja por não garantir plenamente sua execução. Esclarecem esses autores que, na verdade a atuação do Estatuto da Cidade, ficou limitada à aplicação local, servindo, por exemplo, para que alguns municípios o adotassem na elaboração dos Planos Diretores.

A Política Nacional de Mobilidade Urbana tem por objetivo, organizar, coordenar os modos, serviços e infraestrutura de transporte garantido a mobilidade de pessoas e cargas (BARRETO; PORTO, 2016, p. 238). Lorenzetti e Lamounier (2017, p. 67) entendem que mobilidade urbana não se limita ao transporte, sendo necessário pensar-se em todos os

\footnotetext{
${ }^{3}$ Dados obtidos no site <www.camaragov.br/proposicoesweb/fichadetramitacao?idProposicao=501638> Acesso em 8 fev. 2018.
}

Revista de Direito Sociais e Políticas Públicas | e-ISSN: 2525-9881 | Salvador | v. 4 | n. 1 | p. 120 - 138 | 
elementos urbanísticos, tais como calçadas, passeios, faixas de travessia, passarelas. Porque as cidades deveriam ser planejadas para as pessoas, e estas, primordialmente, caminham. De igual modo, Góis $(2012$, p. 80) afirma que a cidade é extremamente automotora, com fluxo caótico de veículos, esquecendo-se que o cidadão é quem habita a cidade, e que a essência da cidade é a socialização entre habitantes.

Nesse rumo, as cidades começam a se adequar às pessoas, especialmente pessoas envelhecidas. Surge então, o Decreto 8.114, de 30 de setembro de 2013, estabelecendo o compromisso nacional com o envelhecimento, através da conjugação do esforço entre os entes federados, contando com a participação da população, da família e da sociedade. Tem por objetivo priorizar políticas e ações destinadas a garantir os direitos da pessoa idosa, fundamentado na emancipação, protagonismo, promoção, defesa, informação e formação. $\mathrm{Na}$ realidade, este decreto não traz nenhuma novidade, pois as diretrizes repetem aquelas já traçadas no Estatuto do Idoso, e de forma muito mais ampla.

De qualquer modo, para a efetivação de todas as legislações seria necessário refundar as cidades, considerando que na realidade brasileira nem todas possuem infraestrutura suficiente nem planejamento adequado para o desenvolvimento. Enquanto isso as intervenções possíveis são relativas à readequação das cidades, pois a cidade será boa para os idosos, quando assim o for para todos (GÓIS, 2012, p. 222).

\section{Sustentabilidade Urbana}

Sustentabilidade é um termo de amplo conhecimento público. No entanto, o seu significado, alcance, abrangência e aplicabilidade são ainda confusos. Torresi; Pardini; Ferreira (2010, editorial) afirmam que a maioria das pessoas tem a percepção de que sustentabilidade está relacionado apenas ao risco atmosférico. Porém, não é exatamente assim, embora esse risco seja o principal. Atualmente o termo é utilizado em diferentes contextos, tornando a expressão polissêmica (FAUSTINO; AMADOR, 2016, p. 2022). Podese então partir do pressuposto que sustentabilidade tem um sentido estrito, em consonância com a sua origem ${ }^{4}$, relacionado com a proteção e a manutenção dos recursos naturais, e um

\footnotetext{
${ }^{4}$ Os conceitos de "sustentabilidade" e de "desenvolvimento sustentável" surgiram nos anos 70, mas tornaram-se mundialmente conhecidos com a publicação do Relatório da Comissão Mundial sobre Meio Ambiente e
} 
sentido amplo, com o termo transportado e adaptado a diferentes âmbitos e contextos (idem, p. 2026). No sentido amplo, implica uma série de pilares, correspondo cada qual a um setor específico (FERRER; GLASENAPP; CRUZ, 2016, p. 1456). Nesse sentido, pode-se verificar que diversos estudos aplicam a sustentabilidade em múltiplos contextos, citando-se a ecológica, ambiental, econômica, social, cultural, política, territorial, jurídica, urbana, tecnológica, empresarial, educacional, entre outros.

Respeitante ao tema do presente trabalho, a sustentabilidade será relacionada à urbanização e à cidade.

Ainda que limitado à urbanização e à cidade, a sustentabilidade é um vocábulo que provoca divergências, ante a existência de diferentes pontos de vista e análise. Assim, é comum encontrar expressões como "ecologia urbana", "urbanismo ecológico", "cidade biofílica" (TÃO, et al., 2017, p. 302 e sg.), quer se refira à urbanização, quer se refira à sustentabilidade e/ou desenvolvimento sustentável. Apesar da polêmica, Faustino; Amador (2016, p.2025) destacam a relação entre sustentabilidade e desenvolvimento sustentável, já que ambos têm algumas características comuns, como o fato de se preocuparem com o meio ambiente, a interdependência nas suas relações com a economia e com a sociedade, o valor da solidariedade e da equidade partilhadas entre gerações e nações, a ênfase dada à participação ativa de todos na solução de problemas.

A Conferência das Nações Unidas para o Desenvolvimento Sustentável - Habitat III, preocupada com o fenômeno da acelerada urbanização, propõe uma Agenda Urbana, organizada sob os seguintes princípios:

Para concretizar nossa visão, resolvemos adotar a Nova Agenda Urbana, orientada pelos seguintes princípios interrelacionados:

(a) Não deixar ninguém para trás, por meio da eliminação da pobreza em todas as suas formas e dimensões, incluindo a erradicação da pobreza extrema, assegurando direitos e oportunidades iguais, diversidade socioeconómica e cultural, integração no espaço urbano, melhoria de habitabilidade, educação, segurança alimentar e nutrição, saúde e bem-estar; inclusive por meio da eliminação de epidemias de SIDA, tuberculose, e

Desenvolvimento da ONU, em 1987, denominado Relatório Brundtland. Nesse documento, o desenvolvimento sustentável foi estabelecido como aquele que satisfaz as necessidades do presente sem comprometer a capacidade das gerações futuras de satisfazerem as suas próprias necessidades. Já a sustentabilidade é qualidade do que é sustentável, podendo ser considerado como objetivo e fim do desenvolvimento ( FAUSTINO; AMADOR, 2016, p. 2023-2024) 
malária, promovendo segurança e eliminando a discriminação e todas as formas de violência; assegurando participação pública ao proporcionar acesso seguro e igualitário a todos; e proporcionando acesso igualitário para todos à infraestrutura física e social e aos serviços básicos, assim como à moradia adequada e economicamente acessível.

(b) Economias sustentáveis e inclusivas, por meio do aproveitamento dos benefícios de aglomeração da urbanização bem-planeada, da alta produtividade, da competitividade e da inovação; promovendo emprego pleno e produtivo e trabalho decente para todos, assegurando a criação de empregos decentes e acesso igualitário para todos a recursos e oportunidades económicos e produtivos; prevenindo a especulação fundiária; e promovendo a posse da terra segura e gerindo a perda de densidade urbana, quando cabível.

(c) Sustentabilidade ambiental, por meio da promoção de energia limpa, do uso sustentável da terra e dos recursos no desenvolvimento urbano, assim como por meio da proteção de ecossistemas e biodiversidade, incluindo a adoção de modos de vida saudáveis em harmonia com a natureza; promovendo padrões de consumo e produção sustentáveis; construindo resiliência urbana; reduzindo o risco de desastres; e mitigando e adaptandose às alterações climáticas. (ONU, 2016, p. 7-8) ${ }^{5}$.

Em consideração a tais princípios, diversos estudos tem sido desenvolvidos, o que contribui para o compreender melhor o desenvolvimento urbano. De acordo com Sachs (apud FAUSTINO; AMADOR, 2016, p. 2025) há oito dimensões principais que alicerçam a sustentabilidade: social, cultural, ecológica, ambiental, territorial, econômica, política nacional e política internacional. A esse rol, pode-se ainda acrescentar a tecnológica, a jurídica e a urbana propriamente dita. Deste rol, Jorge (2015, p. 15) destaca pelo menos três: a econômica, a ambiental e a social, aos quais soma-se a urbana. Por sem dúvida que a economia e o meio ambiente são temas de grande relevância em se tratando de sustentabilidade, contudo, atento ao foco do presente trabalho, serão tratados especificamente sobre a social e a urbana. Evidentemente, os aspectos ambientais estarão presentes neste tratamento, pois a sustentabilidade social e urbana só existirão se for mantida a sustentabilidade ambiental (TORRESI; PARDINI; FERREIRA, 2010, editorial).

Por sustentabilidade social em termos urbanos, entende-se o conjunto de ações que garantam o bem estar das populações, visam reduzir as desigualdades, ampliar os direitos e

\footnotetext{
${ }^{5} \mathrm{O}$ idioma da redação está traduzido para português comumente utilizado nos países africanos, conforme enfatiza o próprio documento.
} 
garantir o acesso aos serviços públicos (JORGE, 2015, p.16). Relaciona-se à participação social na construção de um futuro mais justo, baseado na melhoria da qualidade de vida, com nivelamento de renda, acesso à educação, moradia, alimentação e acessibilidade espacial (SAVI; HESPANHOL, 2017, p. 67). Por isso a sustentabilidade social assume especial relevo no campo do planejamento urbano, funcionamento como instrumento de realização de direitos (JORGE, 2015, p.16).

A expansão da urbanização é uma realidade. O Relatório Mundial das Cidades das Nações Unidas destaca que tanto as pequenas quanto as grandes cidades estão avançando umas sobre as outras, criando megarregiões metropolitanas, configurando uma conexão não só espacial como também funcional. E nesse sentido, a economia, a política e o ambiente se misturam e se combinam, facilitando as comunicações, a troca de conhecimentos e oferecendo oportunidades de desenvolvimento. Contudo, pode levar também a um crescimento desequilibrado, com uma governança ineficaz e fragmentada (ONU (a), 2016, p. 35-36). Para que se possa efetivamente ocorrer o desenvolvimento nos termos definidos no art. 182 da Constituição Federal, objetivando o bem-estar de todos, exige-se um planejamento relacionado à urbanização e à sustentabilidade.

E é nessa linha de raciocínio que o desenvolvimento urbano deve levar em consideração os aspectos da sustentabilidade. O crescimento desordenado das cidades, criando povoamentos aglomerados sem um mínimo de infraestrutura, segurança e conforto, faz com que as condições de vida desses moradores sejam desumanos, acarretando profundas violações dos direitos humanos (JORGE, 2015, p. 17).

Urbanização, etimologicamente, tem relação com a expressão latina urbe, que significa cidade (GARCIAS; BERNARDI, 2008. s/p). Explicam Garcias e Bernardi (2008) que a cidade possui três funções sociais básicas: funções urbanísticas (que incluem a habitação, o trabalho, o lazer e a mobilidade); funções de cidadania (composto pela saúde, educação, proteção e segurança); e funções de gestão (que corresponde a prestação de serviços, o planejamento, a sustentabilidade urbana e a preservação do patrimônio cultural e natural). Jorge (2015,p. 57) afirma que as cidades são construídas, e por isso não são, por natureza sustentáveis. Tão et al. (2017, p. 311) observam que a cidade não é um ambiente exclusivamente humano, havendo inclusive elementos estruturais que possibilitam o contato das pessoas com a natureza. Há, portanto a necessidade de se reinventar e reabilitar as cidades 
(JORGE, 2015, p. 58) de modo a permitir a socialização entre os habitantes, sendo essa a essência das cidades (GÓIS, 2012, p. 83).

Em se tratando de idoso as cidades, segundo premissas da Organização Mundial da Saúde, devem ser amigas, isto é, devem estimular o envelhecimento ativo, otimizando oportunidades de saúde, participação e segurança, de modo que a urbanização considere a inclusão de usuários com diferentes graus de dependência, ser amiga de todas as idades (OMS, 2008, p. 63). Defender a qualidade de vida de uma sociedade, exige desenvolvimento com sustentabilidade.

Sustentabilidade, portanto, na análise de Ferrer; Glasenapp e Cruz (2014, p.1460) pode ser considerado um novo paradigma do direito, na medida em que serve de critério normativo para a reconstrução da ordem econômica, com um sistema econômico mais justo, equilibrado e sustentável; que permite uma organização social ditada pela equidade e justiça social; e um crescimento que respeite o meio ambiente e promova a sobrevivência humana em condições dignas.

\section{Políticas Públicas}

Formular e implementar políticas públicas com vistas a um desenvolvimento urbano sustentável é um desafio para todas as sociedades.

Contudo, os fenômenos da urbanização e do envelhecimento ocorrendo simultaneamente e com ritmos cada vez mais acelerados, urge pensar em políticas públicas com características mais abrangentes e multidisciplinares, proporcionando não apenas aos idosos, mas a toda a população, uma vida habitável com dignidade, reduzindo conflitos e desigualdades, possibilitando conviver com as diferenças e inclusão (PIRES, 2013, p. 129).

Colocando em pauta as diretrizes orientativas da ONU (Habitat-III e Relatório Mundial das Cidades) e da Organização Mundial da Saúde (Cidade amiga do idoso), da Constituição Federal (desenvolvimento urbano) e demais legislações (Estatuto do Idoso, Estatuto da Cidade, Políticas de acessibilidade, entre outeras) as políticas públicas podem ser direcionadas principalmente aos seguintes aspectos: participação, segurança e qualidade de vida. 


\subsection{Políticas públicas visando a participação do idoso}

A participação em diversas atividades é uma das formas para um envelhecimento ativo, conforme orientação da Organização Mundial da Saúde. A participação tem um valor elevado se considerada como uma forma produtiva, não no sentido laboral, mas no sentido social e comunitário (SOUSA, 2016, p. 115). Diversos estudos empíricos demonstram que a participação constitui fator de vida saudável, servindo também como instrumento incentivador da qualidade democrática, na medida em que o envelhecimento ativo inclui participação em atividades familiares, sociais, econômicas, culturais, espirituais e civis (WHO, 2005, p. 52).

Almeida (2015, p. 405) esclarece que as pesquisas sobre participação de idosos podem ser analisadas sob duas linhas principais: na dimensão individual e nas práticas políticas, nas quais muitas vezes demonstram a exclusão, principalmente nessas últimas. Acrescenta a autora ainda que em Portugal, não se tem conhecimento de investigações que tenham como foco a participação cidadã específico para idosos, sugerindo reduzidas oportunidades para essa prática (ALMEIDA, 2015, p. 407).

A participação constitui-se num processo social que contribui para fortalecer os relacionamentos, sendo mesmo requisito para o desenvolvimento do próprio ser humano, enquanto ser social, essencial para o exercício da cidadania, o que implica em permanente aprendizado democrático (KIST; BULLA, 2014, p. 161).

Há diversas formas pelas quais os idosos podem demonstrar participação: no seio familiar, sua contribuição pode se manifestar como apoio emocional e até mesmo financeiro, ao mesmo tempo em que tem sua autoestima valorizada, pois se sentirão úteis e queridos; no âmbito social, embora ainda seja de reduzida expressão, também os idosos atuam em atividades voluntárias ou solidárias, o que reforça sua integração social, suscita atitudes positivas e mantém o sentido de grupo; na seara do trabalho, apesar de se conceber os idosos como aqueles que atingiram a jubilação, muitas vezes, ainda continuam trabalhando ativamente, contribuindo com a riqueza da sociedade, principalmente para a complementação de renda. Pesquisas feitas com idosos economicamente ativos, Rocha (2017, p. 127) concluiu pela desmistificação da ideologia da velhice, pois, esse contingente mantém atividade econômica, não apenas pela recompensa financeira, mas muito mais pela promoção do 
desenvolvimento mental, intelectual, e principalmente, como forma de proteção à longevidade e envelhecimento digno.

Dentre as diferentes formas de participação, talvez a mais complexa, seja a participação política ou civil, como expressão de cidadania.

Almeida (2016, p. 417) define quatro tipos principais de participação cidadã: (i) influência, onde os cidadãos são chamados para opinar em ou um mais aspectos, podendo influenciar na definição do processo em causa; (ii) colaboração, que é uma forma de participação na fase da implementação das políticas; (iii) expressão, que se constitui em iniciativa autônoma que objetiva influenciar os processos de decisão, por exemplo, os movimentos sociais e protestos; e ação, que é uma forma autônoma de ativismo onde cidadãos se mobilizam para atuar diretamente sobre fatos que afetam a vida coletiva, como o movimento de moradores, por exemplo.

Siqueira (2014, p. 171-173) analisa que a participação de idosos no Brasil está muito a desejar: em primeiro lugar, por escassez de recursos orçamentários, o que faz com que as instituições tenham que eleger prioridades em sua aplicação, ficando o grupo de idosos em posição inferior a outros grupos vulneráveis. Esclarece a autora que, embora se tenha um discurso que privilegie a participação dos idosos, os eventos a eles destinados são marcados pela mediação de agentes institucionais e na consolidação das políticas não se dá voz ao idoso, vez que as decisões são organizadas e conduzidas segundo a formatação e o direcionamento do Estado.

$\mathrm{Na}$ maioria dos programas de participação de idosos, estes são públicos-alvos ou beneficiários e nem sempre têm atuação significativa sobre os processos que visam mudanças sociais (ALMEIDA, 2016, p. 412). Nesse sentido, participar, não deve significar somente estar presente, mas influenciar nas decisões que são de seu interesse.

É necessários políticas que estimulem a capacidade de participação dos idosos, que estes se sintam pertencente à comunidade, que os integre e que promovam a sua efetiva inclusão.

\subsection{Políticas públicas de segurança}


A cidade é composta de diversos espaços: espaços abertos, espaços livres, edifícios, residências, comércios, ruas, avenidas, praças, parques, jardins, etc. Todos esses espaços, são geralmente ocupados por diversos idosos que os utilizam como percurso ou como ambiente de lazer. Essas pessoas primordialmente, caminham e, portanto, o caminhar deve ser o mais agradável possível, com manutenção de jardins, parques e prças, bem como instalação de bancos para o descanso dos idosos. O desenho urbano deve levar emconsideração as percepções e sensações das pessoas que irão se utilizar do espaço, pois isso representa segurança para os usuários (LORENZETTI; LAMOUNIER, 2017, p. 69).

Especificamente aos idosos, a insegurança pode afetar sua vontade de sair de casa, principalmente, quando houver algum comprometimento da saúde, razão pela qual, os espaços devem ser limpos, sem desníveis acentuados, facilitar-lhes o acesso. Nesse sentido a acessibilidade constitui-se no fator de grande importância para a segurança dos idosos. A acessibilidade pode constituir-se de quatro componentes: o deslocamento, ou seja, que as pessoas possam se movimentar livremente, com pisos nivelados e antiderrapantes, por exemplo; a orientação, com placas indicativas que esclareçam o sentido e a direção para que os idosos possam compreender o ambiente e se localizarem; as informações, que podem ser visuais, sonoras ou luminosas, além de placas e mapas indicativos; e os usos, informando as restrições, se houver (GÓIS, 2012, p. 79; SAVI e HESPANHOL, 2017, p. 68).

$\mathrm{Na}$ questão da acessibilidade a NBR-9050, da ABNT, fixa padrões e critérios definindo condições adequadas e seguras de acessibilidade autônoma de pessoas com alguma deficiência a edificações, espaços, mobiliários e equipamentos urbanos. Essa adequação, na análise de Góis, 2012, p. 151) tem a ver com atratividade, rampas que auxiliam no deslocamentos, espaços livres de obstáculos, entre outros, que devem ajustar-se às recomendações da antropometria e da biomecânica.

São os diferentes espaços públicos que reforçam a interação social e o sentido de comunidade (MONTEIRO, 2017, p. 27). Sendo a socialização o processo essencial das cidades, os espaços urbanos representam uma parte fundamental para a celebração da vida coletiva nas cidades (GÓIS, 2012, P. 84). Sentir-se seguro para mover-se livremente pela cidade constitui uma vida habitável, que pacifica conflitos, mas principalmente permite conviver com diferenças, induzindo a redução das desigualdades e favorecendo a inclusão (PIRES, 2013, p. 129). 
Existem pontuais políticas públicas direcionadas a adequar as estruturas espaciais, contudo, na maioria das cidades brasileiras, há ainda um descompasso entre a legislação que dispõe sobre acessibilidade e a efetiva intervenção pública para sua prática. Ainda são comuns calçadas com buracos e depressões, pisos inadequados e desnivelados, deficientes transportes públicos, dificultando o deslocamento dos idosos nos centros urbanos. $\mathrm{O}$ direito à mobilidade livre traz satisfação das necessidades às pessoas; assim, embora se tenha em consideração que a organização social e o uso dos espaços não sejam iguais para todos, as ações políticas devem construir espaços onde coexistam distintas trajetórias e obter a melhor qualificação, em respeito à dignidade humana.

Quando os espaços urbanos demonstram condições adequadas, melhoram a qualidade de vida de todos, melhoram a capacidade para envelhecer bem, promovem mudanças construtivas na sociedade e preparam antecipadamente as necessidades do futuros residentes mais velhos (MONTEIRO, 2017, p. 25).

\subsection{Políticas públicas para promover qualidade de vida e sustentabilidade}

Qualidade de vida é expressão de ampla abrangência. A Organização Mundial da Saúde, procura clarificar esse conceito, estabelecendo que:

Qualidade de vida é a percepção que o indivíduo tem de sua posição na vida dentro do contexto de sua cultura e do sistema de valores onde vive, em relação a seus objetivos, expectativas, padrões e preocupações (...) Incorpora a saúde física da pessoa, seu estado psicológico, seu nível de dependência, suas relações sociais, suas crenças e sua relação com o ambiente". (WHO, 2005, p. 14)

A relação entre qualidade de vida e sustentabilidade permite pensar em termos de bem-estar da população idosa. Na promoção do bem-estar diversos elementos estão envolvidos, desde atitudes individuais conscientes como a utilização racional da água, o descarte correto dos resíduos sólidos, até funções coletivas como a preservação do meio ambiente e o desenvolvimento do espírito colaborativo, além das competências sociais e cívicas. Mas, um dos aspectos aqui envolvidos, diz respeito às áreas verdes dos centros urbanos, as quais podem se constituir em simples canteiros centrais que separam as vias, 
jardins verticais em prédios, amplas praças, parques e jardins, ou ainda uma solitária árvore na calçada.

Esses espaços verdes bem cuidados fornecem aos usuários das cidades uma série de benefícios que se relacionam com a saúde e bem-estar.

As plantas são essenciais na manutenção da vida na terra, elas têm a capacidade de renovar o oxigênio do ar, através da fotossíntese, processando uma certa quantidade de carbono $^{6}$ liberado no ambiente pela queima de combustíveis fósseis, sendo apontadas como "principais drenos de carbono" (MARENCO; LOPES, 2005, p. 48).

Os vegetais têm também a capacidade de promover a transpiração, ou seja, expulsão da água em forma de vapor. Esse fenômeno provoca o resfriamento do ar em torno da planta, por isso, em locais por ela sombreados há uma sensação de maior frescor, se comparado com outros espaços com sombra artificial. Segundo Marenco e Lopes (2005, p. 231) algumas árvores podem ter uma taxa de transpiração equivalente a $30 \mathrm{~kg}\left(\mathrm{H}_{2} \mathrm{O}\right)$ por hora, mantendo a unidade e a temperatura do ambiente em níveis inferiores em comparação com espaços abertos e ensolarados.

As plantas possuem ainda a capacidade de amortecer ondas de som no ambiente. Assim, a presença delas no meio urbano constitui verdadeira barreira para minimizar a poluição sonora tão comum nas cidades.

Some-se ainda a redução da cobertura vegetal nas cidades, com a superação do índice de impermeabilização pela construção de prédios, de ruas, asfaltos, calçadas, a qual, por sua vez concorre para a ocorrência de enchentes e alagamentos. Nesse sentido, observa Moesch (2006, p. 684), que a supressão da cobertura vegetal das cidades é preocupante, pois contribui também para a fragmentação e destruição de hábitats de espécies de animais que ainda sobrevivem nesses ecossistemas.

Considerando que as praças, parques e jardins, tornam-se locais de encontro, de interação social entre as pessoas, principalmente idosos que têm esses espaços, como locais de passeio e recreação, é importante a presença de plantas bem cuidadas, pois estas podem promover sombra e frescor em dias quentes de verão, podem abrir-se em flor, em sua estação

\footnotetext{
${ }^{6} \mathrm{O}$ carbono é um componente químico, prejudicial à saúde humana, um dos responsáveis pela retenção do calor na atmosfera terrestre, chamada efeito estufa.
}

Revista de Direito Sociais e Políticas Públicas | e-ISSN: 2525-9881 | Salvador | v. 4 | n. 1 | p. 120 - 138 | 
primaveril, além de atrair insetos e aves em busca de alimentação e pousada, os quais se transformam em metas de observação e interesse. Esses ambientes, sem dúvida, com atmosfera renovada e saudável podem trazer melhor bem-estar a todos. No entanto, Tão et al. (2017, p. 305) afirmam que não basta a existência de elementos que possibilitem o contato com a natureza, sendo também necessário ações educativas e programas de formação que aproximem a população desses espaços e os dotem de significados para que não haja subutilização e abandono.

\section{Conclusão}

Envelhecimento e urbanização são dois temas que despertam preocupação e grande interesse de pesquisadores em diferentes áreas de conhecimento, pois ambos são fenômenos reais que acarretam impactos nos diversos setores da vida humana.

As legislações avançam no intuito de estabelecer normas que promovam o desenvolvimento urbano, mas também respeitem os direitos dos cidadãos, principalmente dos idosos.

Observam-se ações pontuais de adequação das cidades às pessoas envelhecidas, influenciadas pelas orientações do Guia Global Cidade Amiga do Idoso, proposto pela Organização Mundial da Saúde, conjugando esforços para garantir os direitos da pessoa idosa.

Elaborar políticas públicas abordando de forma convergente que contemple, complementarmente os temas envelhecimento e urbanização é um desafio a todas as sociedades.

Para que as cidades ofereçam uma vida habitável com dignidade, será necessário políticas públicas abrangentes, multidisciplinares, de modo a promover mudanças estruturais nas cidades atuais, eleger estratégias éticas, com planejamento e efetividade nas execuções e o respeito total às normas legislativas e princípios internacionais orientadores para a defesa e dignidade das pessoas humanas, em especial o das pessoas idosas.

\section{Referências}


ALMEIDA, Mariana Ferreira de. Iniciativas de participação cidadã de idosos em Portugal: um estudo exploratório. Análise Social, n. 219, vol. LI (2º), p. 401-431, 2016. Disponível em $<$ http://www.scielo.mec.pt/scielo.php?script=sci arttext\&pid=S0003...> Acesso em 8 fev. 2018.

BARRETO, Jorge Barbosa; PORTO, César Henrique de Queiroz. Mobilidade urbana, acessibilidade e segurança no trânsito para população idosa em Montes Claros - MG. Revista Cerrados, v. 14, n.2, p. 230-249, Montes Claros, jul-dez/2-16. Disponível em <www.periodicos.unimontes.br/cerrados> Acesso em 8 fev. 2018.

DRAIBE, Sonia M.; RIESCO, Manuel. Estados de bem-estar social e estraégias de desenvolvimento na América Latina: um novo desenvolvimento em gestação? Sociologias, ano 13, n. 27, p. 220-254, Porto Alegre, maio-ago/2011. Disponível em <www.scielo.br/pdf/soc/v13n27/a09v13n27.pdf. Acesso em 8 fev. 2018.

FAUSTINO, Manuel; AMADOR, Filomena. O conceito de sustentabilidade: migração e mudanças de significados no âmbito educativo. CIDFF - Indagatio Didacticca, v. 8, n. 1, p. 2021-2033. julho/2016. Disponível em 〈http://www.revistas.ua.pt > Capa > v. 8, n. 1 (2016) > Faustino > Acesso 8 fev. 2018.

FERRER, Gabriel Real; GLASENAPP, Maikon Cristiano; CRUZ, Paulo Márcio. Sustentabilidade: um novo paradigma para o direito. Revista Novos Estudos Jurídicos [eletrônica], v.19, n.4, p. 1433-1464, Edição Especial, 2014. Disponível em <www.univali.br/periodicos Doi: 10.14210/nej.v19n4.p1433-1464 > Acesso em 8 fev. 2018.

GARCIAS, Carlos Mello. BERNARDI, Jorge Luiz. As funções sociais da cidade. Revista de Direitos Fundamentais e Democracia, v. 4, 2008. Disponível em 〈http://www.revistaeletronicardfd.unibrasil.com.br/index.php/rdfd/article/viewFile/48/47> Acesso em 8 fev. 2018.

GÓIS, Ronald lima de. A cidade e o idoso: parâmetros para dimensionamento em arquitetura e urbanismo. Tese de Doutorado em Arquitetura e Urbanismo. Universidade Federal do Rio Grande do Norte, 2012. Disponível em <https://repositorio.ufrn.br/jspui/bitstream/123456789/12300/1/RonaldLG_TESE.pdf> Acesso em 8 fev. 2018.

IBGE - Instituto Brasileiro de Geografia e Estatística. Síntese dos Indicadores Sociais - uma análise das condições de vida da população brasileira, no 36, IBGE - Instituto Brasileiro de Geografia e Estatística, 2016. Disponível em <www.ibge.org.br> Acesso em 2 maio 2017.

JORGE, Miriam Jose Fernandes. A cultura da sustentabilidade social, um instrumento de humanização. Dissertação de Mestrado em Direito. Universidade de Coimbra, Portugal, janeiro 2015. Disponível em <https://estudogeral.sib.uc.pt/.../A\%20cultura\%20da\%20sustentabilidade\%20social.pdf> Acesso em 8 fev. 2018. 
KIST, Rosane Bernadete Brochier; BULLA, Leonia Capaverde. A participação em espaços coletivos e a autonomia dos idosos. Temporalis, ano 14, n. 28, p. 151-171, Brasília, juldez/2014. Disponível em

$<$ http://www.periodicos.ufes.br/temporalis/article/download/7208/6150> Acesso em 8 fev. 2018.

LORENZETTI, Maria Silvia Barros; LAMOUNIER, Ludimila Penna. Perspectivas quanto à mobilidade e ao espaço urbano em função do envelhecimento da população brasileira. In:

2050 - Desafios de uma nação que envelhece. Centro de Estudos e Debates Estratégicos. Brasília: Câmara dos Deputados, Edições Câmara, 2017. Disponível em <www.livraria.camara.leg.br > Acesso em 8 fev. 2018.

MARENCO, Ricardo Antonio; LOPES, Nei Fernandes. Fisiologia vegetal: fotossíntese, respiração, relações hídricas, nutrição mineral. Viçosa (MG): UFV, 205. 451p.

MOESCH, Beto. O licenciamento ambiental como ferramenta para conservção da vegetação em Porto Alegre. In: MARIATH, Jorge Ernesto de Araujo (org.); SANTOS, Rinaldo Pires dos. (org.). Os avanços da botânica no início do século XXI. Porto Alegre: Sociedade Botânica do Brasil, 2006. 752p.

MONTEIRO, Andreia Marisa de Oliveira. O contributo do espaço público para o envelhecimento ativo na cidade do Porto: da percepção à realidade. Dissertação de Mestrado em Sistema de Informação Geográfica e Ordenamento de Territorio, Faculdade do Porto, 2017. Disponível em <https://repositorio-aberto.up.pt/handle/10216/108867> Acesso em 8 fev. 2018.

OLIVEIRA, Felipe Morais de. Bases informacionais para o desenvolvimento - as contradições na economia e as alternativas atuais. Dissertação de Mestrado em Economia Política. Pontifícia Universidade Católica de São Paulo, 2017. Disponível em $<$ https://sapientia.pucsp.br/bitstream/handle/.../2/Felipe\%20Morais\%20de\%20Oliveira.pdf $>$ Acesso em 8 fev. 2018.

OMS - Organização Mundial da Saúde. Guia Global: cidade amiga do idoso. Genebra: Organização Mundial da Saúde, 2008, 67p. Disponível em

<www.who.int/ageing/GuiaAFCPortuguese.pdf> Acesso em 8 fev. 2018.

ONU - Organização das Nações Unidas. Habitat-III - Nova Agenda Urbana. Quito, Equador, 2016 [traduzido para o português com vocabulário técnico utilizado nas nações africanas]. Disponível em <http://www.habitat3.org/wp-content/uploads/NUA-PortugueseAngola.pdf> Acesso em 8 fev. 2018.

World population prospects: the 2017 revision. Working paper $n$.

ESA/P/WP/248. New York: United Nations, 2017. 46 p. Disponível em <https://esa.un.org/unpd/wpp/.../Files/WPP2017_KeyFindings.pdf> Acesso em 6 ago. 2017.

(2) World cities report 2016: Urbanization and development - emerging futures. United Nations Humans Settlements Programe - UN-Habitat. New York: United Nations, 2016, 247p. Disponível em 〈https://www.unhabitat.org> Acesso em 8 fev. 2018. 
PIRES, Fátima Lauria. Mobilidade e direitos sociais: uma questão de justiça na cidade. Tese de Doutorado em Política Social. Universidade de Brasília, 2013, 148p. Disponível em 〈http://www.repositorio.unb.br/bitstream/10482/13628/1/2013_FatimaLauriaPires.pdf> Acesso em 8 fev. 2018.

PRONI, Marcelo Weishaupt; FAUSTINO, Raphael Brito. Avanços e limites da política de desenvolvimentourbano no Brasil (2001-2014). Planejamento e Políticas Públicas, n. 46, p. 181-215, jan-jun/2016. Disponível em <www.ipea.gov.br> Acesso em 8 fev. 2018.

ROCHA, Sheila Marta Corregosa. Pessoas idosas no mercado de trabalho: garantia de sua dignidade. Salvador, Bahia, 2017, 167p.

SAVI, Aline Eyng; HESPANHOL, Lays Juliani. Sustentabilidade social através da acessibilidade em espaços livres, metodologia de análise e proposição nos passeios públicos. Mix Sustentável, v. 3, n. 2, p. 66-73, Florianópolis, maio, 2017. Disponível em <http://www.nexos.ufsc.br/index.php/mixsustentavel/article/view/1923> Acesso em 8 fev. 2018.

SIQUEIRA, Monalisa Dias de. Vivendo bem até mais que 100 - envelhecimento, saúde e políticas públicas para idosos. Tese de Doutorado em Antropologia Social. Universidade Federal do Rio Grande do Sul. Porto Alegre, 2014. 214p. Disponível em <http://www.lume.fgrgs.br/bitstrean/id/380721/000920988.pdf> Acesso em 24 jul. 2017.

SOUSA, Ana Maria Viola de. Direito ao envelhecimento. Lisboa, Portugal: Chiado Editora, 2016. 196p.

TÃO, Nicolas Guerra Rodrigues, et al. Convergências dos campos urbanos e ambiental em propostas conceituais que visam a sustentabilidade urbana: avanços e desafios. Thesis, v. 2, n. 3, p. 299-317, Rio de Janeiro, jan-out/2017. Disponível em < http://www.anparq.org.br/dvdenanparq-4/.../S44-06-RODRIGUES\%20TAO,\%20N;...pdf> Acesso em 8 fev. 2018.

TORRESI, Susana I.Córdoba de; PARDINI, Vera L.; FERREIRA, Vitor F. O que é sustentabilidade? Revista Química Nova, v. 33, n. 1. Editorial, 2010. Disponível em <http://www.scielo.br> Acesso em 8 fev. 2018.

WHO - World Health Organization. Envelhecimento ativo: uma política de saúde. Título origial Active ageing: a policy framework. Tradução de Suzana Gontijo. Brasília:

Organização Pan-Americana da Saúde, 2005, 60p. 